\title{
Artikel
}

\section{Verdwenen alleenstaande minderjarige vluchtelingen: voer voor mensenhandelaren?}

\author{
Prof. dr. M. Smit en dr. mr. E.C.C. van Os*
}

Volgens het internationale onderzoeksjournalistiekcollectief Lost in Europe zouden er in 20177.024 alleenstaande vluchtelingenkinderen zijn verdwenen uit asielzoekerscentra in Europa. Dit aantal is niet wetenschappelijk onderbouwd, maar dat dergelijke verontrustende verdwijningen geregeld voorkomen, is zeker. Wat wordt er tegen het verdwijnen van alleenstaande minderjarige vluchtelingen gedaan en wat is er bekend over het lot van verdwenen jongeren? Vaak worden er zorgen geuit dat deze kinderen slachtoffer zijn of worden van mensenhandel. In hoeverre zijn daar aanwijzingen voor? In deze bijdrage gaan we in op deze vragen. Na een korte introductie over alleenstaande minderjarige vluchtelingen en mensenhandel, besteden we aandacht aan verdwijningen buiten en binnen Nederland. Vervolgens doen we verslag van de bevindingen uit een aantal onderzoeken en van in Nederland getroffen maatregelen tegen verdwijningen. We ronden af met een conclusie en enkele aanzetten voor preventie van verdwijningen.

\section{Alleenstaande minderjarige vluchtelingen}

Van de ruim 82 miljoen mensen op de vlucht, hebben er meer dan 26 miljoen hun land verlaten. Ongeveer de helft daarvan is jonger dan 18 jaar. ${ }^{1}$ Een deel van deze

Prof. dr. M. Smit is bijzonder hoogleraar psychosociale zorg voor alleenstaande minderjarige vreemdelingen aan de Rijksuniversiteit Groningen. Dr. mr. E.C.C. van Os is docent en onderzoeker (ortho)pedagogiek en kinderrechten aan de Rijksuniversiteit Groningen.

1

www.unhcr.org/figures-at-a-glance.html.

kinderen reist zonder ouders of andere voor hen verantwoordelijke volwassenen of is onderweg gescheiden van hen geraakt: alleenstaande minderjarige vluchtelingen. Er zijn geen gesegregeerde cijfers over kinderen die met en zonder ouders op de vlucht zijn. De meeste (> 750.000) minderjarige gevluchte kinderen bevinden zich in Ivoorkust, Guinee Bissau, Oeganda, Tunesië, Turkije en het Verenigd Koninkrijk. ${ }^{2}$ In 2020 deden in totaal 416.600 mensen een (eerste) asielverzoek in landen van de Europese Unie, 129.630 van hen waren minderjarig en daarvan waren er 13.482 alleenstaand. ${ }^{3}$

In Nederland vroegen in 2020986 alleenstaande jongeren asiel aan, de meesten kwamen uit Syrië en Marokko. ${ }^{4}$ Het gaat vooral om jongens en de meesten (55\%) zijn bij aankomst 14 jaar of ouder. ${ }^{5}$ Een deel van de alleenstaande minderjarigen die naar Europa komen, 'verdwijnt' op enig moment. Om hoeveel jongeren het gaat, is moeilijk precies vast te stellen omdat niet alle vermissingen worden geregistreerd en de wel beschikbare cijfers niet vergelijkbaar zijn tussen landen (EMN, 2020). Verdwenen kinderen zijn bijzonder kwetsbaar ${ }^{6}$ en er bestaan zorgen dat zij in handen van mensenhandelaren terechtkomen. ${ }^{7}$

Ontvangende landen, waaronder Nederland, hebben een kinderrechtelijke verantwoordelijkheid voor ver- 
dwenen alleenstaande minderjarigen. Op het moment van verdwijnen staan de alleenstaande minderjarigen in Nederland meestal onder gezag van Nidos. Minderjarigen die (tijdelijk) niet in hun ouderlijk gezin kunnen wonen, hebben recht op bijzondere bescherming (art. 20 IVRK). Dat geldt ook voor degenen die asiel hebben aangevraagd (art. 22, lid 1, IVRK). Nederland heeft de plicht om hen actief bij te staan bij het zoeken naar hun ouders en overige gezinsleden. Als dat niet lukt, dan zijn voor hen de reguliere kinderbeschermingsstandaarden van toepassing (art. 22, lid 2, IVRK).

\section{Mensenhandel}

Omdat de mogelijkheden voor reguliere migratie beperkt zijn en de reis vaak gevaarlijk is, zijn migranten - onder wie minderjarige vluchtelingen - voor hun reis veelal afhankelijk van mensensmokkelaars. ${ }^{8}$ Smokkelaars vervullen een brugfunctie tussen gevaarlijke of armere landen en veilige, welvarender gebieden. Zij helpen betrokkenen om op niet-reguliere wijze grenzen over te gaan. Sommigen doen dat uit humanitaire motieven (om familie, vrienden of vluchtelingen te helpen), ${ }^{9}$ anderen uit winstoogmerk.

Meestal eindigt de relatie tussen smokkelaar en gesmokkelde na aankomst in het bestemmingsland. Het komt echter ook voor dat hulp bij de verplaatsing - waarbij niet altijd een grens wordt overschreden - gebeurt met het oogmerk van uitbuiting. In dat geval is er sprake van mensenhandel. De relatie tussen mensenhandelaar en slachtoffer is dan na aankomst nog niet voorbij; er wordt eerst nog aan het slachtoffer verdiend. Mensensmokkel en -handel zijn soms moeilijk van elkaar te onderscheiden en smokkel kan overgaan in handel, maar het gaat wel degelijk om verschillende fenomenen. ${ }^{10}$ Volgens de definitie in het VN Protocol inzake voorkoming, bestrijding en bestraffing van mensenhandel, in het bijzonder vrouwen- en kinderhandel (2000), is mensenhandel: 'het werven, vervoeren, of onderbrengen van personen, gebruikmakend van dreiging of geweld, misleiding of misbruik van macht of een kwetsbare positie, met het oogmerk van uitbuiting' (art. 3a).

Het gaat om uitbuiting in de prostitutie, andere vormen van seksuele uitbuiting, gedwongen arbeid of diensten, slavernij, praktijken die vergelijkbaar zijn met slavernij, onderworpenheid en de verwijdering van organen. Ook uitbuiting door slachtoffers te dwingen tot criminele activiteiten of bedelarij zijn vormen van mensenhandel.

8 E. Aloyo \& E. Cusumano, 'Morally evaluating human smuggling: the case of migration to Europe', Critical Review of International Social \& Political Philosophy, 2021 24(2), p. 133-156; A. Geddes \& P. Scholtes, The politics of migration \& immigration in Europe. Londen 2016: Sage.

9 I. van Liempt, Navigating Borders. Inside perspectives on the process of human smuggling into the Netherlands. Dissertatie UvA 2007

10 E.R. Kleemans, \& M. Smit, 'Human smuggling, human trafficking, and exploitation in the sex industry' in: L. Paoli, The Oxford Handbook of Organized Crime. Oxford University press 2014.
Als de uitbuiter de genoemde dwangmiddelen hanteert, maakt het niet uit of het slachtoffer wel of niet instemt met de uitbuiting. Het eerste facultatief protocol bij het Internationaal Verdrag inzake de Rechten van het Kind (IVRK) maakt onderscheid tussen de handel in kinderen, kinderprostitutie en -pornografie en noemt ook illegale adoptie als uitbuitingsvorm (art. 3). Anders dan bij volwassenen, hoeft er bij minderjarige slachtoffers geen gebruik te zijn gemaakt van dwang of geweld om van mensenhandel te kunnen spreken. Het Wetboek van Strafrecht sluit aan bij bovengenoemde definities (art. $273 \mathrm{f}$, lid 1). Als het slachtoffer minderjarig is, staat er vijftien jaar gevangenisstraf op mensenhandel (art. 273 f, lid 3).

\section{Verdwijningen van minderjarigen buiten Nederland}

Hoewel de precieze omvang van het fenomeen niet bekend is, is er de laatste jaren wereldwijd meer aandacht gekomen voor de verdwijning van alleenstaande minderjarige vluchtelingen. Dit vanuit bezorgdheid en de vrees dat een deel van hen slachtoffer wordt van mensenhandel. UNODC meldde in het 2020 Global Report on Trafficking in Persons dat wereldwijd één op de drie geregistreerde slachtoffers van mensenhandel minderjarig is. In lagelonenlanden gaat het vooral om gedwongen (kinder)arbeid; in hogelonenlanden, waar het percentage minderjarige slachtoffers overigens veel lager ligt, worden slachtoffers vaker teruggevonden in situaties van seksuele uitbuiting. Risicofactoren op slachtofferschap van uitbuiting zijn het ontbreken van ouderlijke zorg, een disfunctionele gezinsachtergrond, armoede, thuisloosheid en de mede door Covid-19 veroorzaakte slechte economische situatie in veel landen. Volgens de UNODC-cijfers, die ook Europese slachtoffers betreffen, was 21\% van de in 2018 in West- en Zuid-Europa geidentificeerde slachtoffers van mensenhandel een minderjarige jongen en 14\% een minderjarig meisje. Er was sprake van een toename die onder meer toegeschreven wordt aan gegroeide drugssmokkel in het Verenigd Koninkrijk, waar ook minderjarigen bij betrokken worden.

Op verzoek van de Europese Commissie deed het Europees Migratienetwerk (EMN) onderzoek naar vermissingen van alleenstaande minderjarige vreemdelingen binnen de Europese lidstaten en naar de wijze waarop daarmee wordt omgegaan. In de meeste lidstaten wordt uitgegaan van een vermissing wanneer een jongere verdwenen is uit de opvang, niet bekend is waar hij of zij is, de jongere plotseling niet meer te bereiken is en de verdwijning ongewoon is. Bijna alle lidstaten geven volgens het EMN-onderzoek aan procedures te hebben die bepalen wanneer vermissingen gerapporteerd moeten worden (meestal binnen 24 uur), wie dat moet doen (gewoonlijk is het de laatste persoon of instantie die contact had met de jongere vóór de verdwijning) en wie verantwoordelijk is voor het vervolg (meestal de politie). 
Diverse landen geven aan amber alerts te gebruiken en vermissingen van vreemdelingen door te geven in het Schengen Informatie Systeem (SIS).

Gevraagd om een reactie op deze bevindingen van het EMN geven ngo's aan dat de genoemde procedures, anders dan bij vermissing van uit het desbetreffende land zelf afkomstige kinderen, in de praktijk niet altijd worden gevolgd. Daarbij speelt onvoldoende samenwerking tussen de verschillende autoriteiten, die bovendien niet allemaal goed getraind zijn op dit onderwerp, een rol. Vaak maakt een risicoanalyse deel uit van de procedure - gebaseerd op factoren als leeftijd, sekse, land van herkomst en verblijfsstatus - maar volgens de ngo's varieert de kwaliteit van de risicoanalyses in de praktijk. ${ }^{11}$ En je kunt je afvragen of de vermissing van een minderjarige op zichzelf niet zorgwekkend genoeg is.

\section{Verdwijningen in Nederland}

Ook in Nederland verdwijnen er alleenstaande kinderen die asiel hebben aangevraagd. Dat is geen nieuw verschijnsel. Het Jaarverslag 1995 van De Opbouw, de voorloper van Nidos, de voogdijvoorziening voor onbegeleide minderjarigen in Nederland, meldt al dat onzekerheid over de verblijfsstatus 'motivatieproblemen' veroorzaakt, wat kan leiden tot schoolverzuim en 'onverwacht vertrek' (p. 22). In het Jaarverslag 1999 staat dat in de prevoogdijfase geregeld jongeren vertrekken uit de centrale opvang en dat de redenen daarvoor moeilijk in te schatten zijn. Voorts staat vermeld dat van verdwijningen altijd melding wordt gemaakt bij de vreemdelingenpolitie en dat aangifte van vermissing wordt gedaan. In het Jaarverslag 2005 van - dan inmiddels Nidos, staat dat een groot deel van $22 \%$ van de pupillen bij wie als verblijfplaats 'divers' staat vermeld, 'met onbekende bestemming' is vertrokken. Als een van de oorzaken werd het ingaan van de regeling beëindiging voorzieningen genoemd: 'Jongeren weten dat op hun $18 \mathrm{e}$ verjaardag de begeleiding vanuit Nidos stopt en besluiten veelal voor die datum te vertrekken', aldus het Jaarverslag.

\section{Pilot Beschermde Opvang}

In de periode 2004-2005 verdwenen er in een jaar tijd 125 Indiase alleenstaande minderjarigen uit de grootschalige campussen. Enkele jaren later was dat het geval bij ongeveer 140 Nigeriaanse jongeren, onder wie meer dan 100 meisjes. De vrees bestond dat zij het slachtoffer waren geworden van mensenhandel. In reactie op de verdwijningen werden meerdere maatregelen getroffen. Er startte een grootschalig opsporingsonderzoek, Kool-

11 European Migration Network, Missing unaccompanied minors in the EU member states, Norway and the United Kingdom - EMN Inform. Brussel 2020: European Migration Network. vis geheten, waaruit bleek dat de Nigeriaanse meisjes naar Nederland waren gehaald, vaak met gebruik van voodoo als pressiemiddel, om hen hier of in het buitenland uit te buiten in de prostitutie. Verder werd de beveiliging op de campussen aangescherpt en kwam er een pilot 'Beschermde Opvang' voor alleenstaande minderjarigen vanaf 13 jaar, die slachtoffer (zouden kunnen) zijn of dreigen te worden. De pilot bestond uit kleinschalige centra, die jongeren alleen met toestemming of onder begeleiding mochten verlaten, en waar zij intensief werden begeleid. Een van de doelen van de pilot, die begin 2008 formeel van start ging met 45 opvangplaatsen verdeeld over vijf locaties, was het aantal verdwijningen te reduceren. Jeugdbeschermers van Nidos in Ter Apel screenden nieuw gearriveerde minderjarigen om te bepalen of sprake was van risico's en plaatsing in de Beschermde Opvang wenselijk was. In dat eerste jaar werden er 170 jongeren (van wie twee derde deel meisjes) in de Beschermde Opvang geplaatst.

Het WODC evalueerde de pilot Beschermde Opvang. ${ }^{12}$ Vastgesteld werd dat er grofweg twee typen vermoedelijke slachtoffers in de Beschermde Opvang verbleven: jongeren die eerder waren misbruikt waarbij een aspect van mensenhandel speelde en jongeren die bestemd leken om na aankomst in Nederland uitgebuit te worden. In de meeste gevallen waren er geen harde aanwijzingen voor slachtofferschap van mensenhandel en er werd ook maar in enkele gevallen opsporingsonderzoek gestart op basis van hun verklaringen. Opsporen en vervolgen van mensenhandelaren is sowieso moeilijk omdat slachtoffers uit bijvoorbeeld schaamte, of angst voor de handelaren of voor uitzetting, niet altijd hun (hele) verhaal vertellen en de bewijsvoering in mensenhandelzaken is, mede daardoor, vaak moeilijk rond te krijgen. ${ }^{13}$ Als jongeren in de beschermde opvang al aangifte doen, dan levert dat zelden opsporingsindicaties op. Vaak lijken verhalen op elkaar, wat erop kan duiden dat betrokkenen geen slachtoffers zijn van mensenhandel of dat zij een verhaal reproduceren dat mensenhandelaars hen voorlegden..$^{14}$ Daarnaast doen jongeren veelal, op advies van hun advocaat, geen aangifte, maar dienen een asielverzoek in (Jaarverslag Nidos, 2018). In het WODConderzoek werd voorts geconcludeerd dat het aantal verdwijningen van jongeren afnam en dat voor de vrijheidsbeperking in de Beschermde Opvang een wettelijke grondslag ontbrak.

In 2010 werd besloten de Beschermde Opvang voort te zetten, waarbij werd gewerkt aan de knelpunten die in het evaluatieonderzoek waren geconstateerd. Veiligheidsmaatregelen in de Beschermde Opvang werden versoepeld en er werd een meer ontspannen sfeer gecre-

12 A.M. Galloway, E.M.Th. Beenakkers, B. Kamstra \& R. Aidala, Tussen beheersing en begeleiding (Cahier 2010-6), Den Haag 2010: WODC.

13 Zie bijvoorbeeld de eerste rapportages van de Nationaal Rapporteur Mensenhandel, waaronder BNRM 2002, p. 144-149.

14 Nationaal Rapporteur Mensenhandel en Seksueel Geweld tegen Kinderen, Mensenhandel: Naar een kindgericht beschermingssysteem voor alleenstaande minderjarige vreemdelingen. Den Haag 2015: Nationaal Rapporteur. 
eerd. Ook kwam er meer aandacht voor psychische bijstand voor de jongeren. ${ }^{15}$ Omdat jongeren na een aantal maanden overgeplaatst worden naar de reguliere opvang werd in het hiervoor aangehaalde onderzoek van de Nationaal Rapporteur Mensenhandel nagegaan hoeveel van de 163 jongeren die in 2011-2012 waren ingestroomd in de Beschermde Opvang, alsnog verdwenen uit de vervolgopvang. Dat bleek drie keer te zijn voorgekomen. Of deze jongvolwassenen (opnieuw) in handen gevallen zijn van mensenhandelaren, is onbekend. Er verdwijnen overigens ook jongeren uit de reguliere opvang, soms na het ontvangen van een negatieve beslissing op hun verblijfsaanvraag, of wanneer zij geen verblijfsrecht (meer) hebben en de 18e verjaardag nadert. Dat is het moment waarop zij geen aanspraak meer kunnen maken op opvang en teruggestuurd kunnen worden, ook als er geen adequate opvang in het land van herkomst is. Uit een recent onderzoek bleek dat negen geinterviewde alleenstaande minderjarigen zonder verblijfsstatus die waren verdwenen uit de reguliere opvang dit bijna allemaal hadden gedaan omdat zij op hun $18 \mathrm{e}$ werden geacht Nederland te verlaten en uitzetting dreigde, terwijl zij zelf hun toekomst in Nederland zagen. ${ }^{16} \mathrm{Bij}$ hen zijn er geen aanwijzingen voor slachtofferschap mensenhandel, zij verkiezen de illegaliteit boven gedwongen terugkeer. Wel is het de vraag hoe deze jongeren zonder verblijfsrecht overleven en is het duidelijk dat zij door hun situatie kwetsbaar zijn voor uitbuiting. Mentoren en jeugdbeschermers zijn soms op de hoogte van de verblijfplaats of (waarschijnlijke) bestemming van jongeren die op papier zijn verdwenen. ${ }^{17}$ Jongeren hebben hen dan laten weten dat ze naar familie elders in Europa zouden gaan of dat ze ergens in Nederland verblijven. ${ }^{18}$ Maar er zijn ook voogden die melden dat jongeren teruggevonden zijn in een uitbuitingssituatie in Nederland of elders in Europa. ${ }^{19}$ In een eerder onderzoek waarin met 118 illegaal verblijvende voormalige alleenstaande minderjarige vreemdelingen werd gesproken over hoe zij voorzien in hun bestaan, werden twee slachtoffers van mensenhandel aangetroffen. ${ }^{20}$

15 M. Galloway, M. Smit \& M. Kromhout, 'Between Control and Support. The Protection of Unaccompanied Minor Asylum Seekers at Risk: The Dutch Case' in: International Migration 2014, jrg. 53, nr. 4, p. 51-61.

16 I. Kulu-Glasgow, M. van der Meer, M. Smit \& S.M. Noyon, Een onzekere toekomst (cahier 2021-17), Den Haag 2021: WODC.

17 Nationaal Rapporteur Mensenhandel en Seksueel Geweld tegen Kinderen, Mensenhandel: Naar een kindgericht beschermingssysteem voor alleenstaande minderjarige vreemdelingen, Den Haag 2015: Nationaal Rapporteur.

18 E.M. van Wijk-Zielstra, M.A.E. Thomeer-Bouwens \& M. Smit, Ik heb het achter mijn rug gezet: voormalige alleenstaande minderjarige asielzoekers in Nederland, Universiteit Leiden 2001.

19 M. Kaandorp \& M. Blaak, Kinderhandel in Nederland De aanpak van kinderhandel en de bescherming van minderjarige slachtoffers in Nederland, Voorburg/Leiden 2013: UNICEF/Defence for Children.

20 R. Staring \& J. Aarts, Jong en illegaal in Nederland, Den Haag 2010: WODC.

\section{Nederlandse onderzoeken naar verdwijningen}

Naar aanleiding van de verdwijning van Vietnamese jongeren uit de Beschermde Opvang en een radio-uitzending daarover van het programma Argos in maart 2019, zijn twee onderzoeken gedaan. Het ene door de Analyse Proeftuin Migratieketen (APM), ${ }^{21}$ een samenwerkingsverband van partners binnen de migratieketen, het andere door het Expertisecentrum Mensensmokkel en Mensenhandel (EMM), ${ }^{22}$ een samenwerkingsverband tussen de Nationale Politie, de Koninklijke Marechaussee, de Immigratie- en Naturalisatiedienst en de Inspectie van het ministerie van Sociale Zaken en Werkgelegenheid.

Het APM-onderzoek richtte zich op alle jongeren die in de periode 2015 tot en met 2018 uit de verschillende typen asielopvang (waaronder de Beschermde Opvang) met onbekende bestemming zijn vertrokken. Het gaat om 1.750 jongeren, $20 \%$ van alle door COA en Nidos opgevangen jongeren in die periode. Het merendeel is jongen (88\%), de meesten kwamen uit Marokko (260), Afghanistan (240) en Eritrea (170). Tachtig jongeren kwamen uit Vietnam. Het merendeel van de jongeren vertrekt binnen een halfjaar na registratie van binnenkomst, ongeveer de helft al voor de beslissing van de IND op hun (eerste) asielaanvraag. Meer dan de helft (64\%), vooral jongeren uit Marokko, Algerije en Eritrea, is eerder in een andere EU-lidstaat aangetroffen. En ook meer dan de helft (59\%) wordt binnen twee maanden na de registratie van hun verdwijning door de politie aangetroffen, vooral in gemeenten met (voormalige) opvanglocaties en/of de grote steden. Een aantal jongeren is voor (90 jongeren) of na (20 jongeren) hun vertrek door de KMar aangetroffen als 'inklimmer' in een vrachtwagen, bij een poging om als verstekeling het Verenigd Koninkrijk te bereiken. Voor bijna een kwart van de geanalyseerde groep is een Dublinclaim ontvangen uit andere Europese landen. Alleenstaande minderjarigen zonder familie in een ander EU-land mogen in beginsel niet geclaimd worden: hun recht op continuiiteit krijgt voorrang boven de Dublin-afspraken. Als elders in de EU gezins- of familieleden asiel hebben aangevraagd, dan mag er wel een Dublin-claim gelegd worden. Daarbij moet een individuele 'belang van het kind-assessment' worden uitgevoerd.

APM heeft op basis van de resultaten de indruk dat een groot deel van de geanalyseerde groep rondreist binnen de Europese Unie en niet de intentie heeft om lang in Nederland te verblijven. Het onderzoek is gebaseerd op analyse van registratiesystemen van de betrokken instellingen en werpt geen licht op motieven van de jon-

21 Ministerie van Veiligheid \& Justitie, APM Analyse: Alleenstaande minderjarige vreemdelingen die met onbekende bestemming vertrekken, 2019.

22 Expertisecentrum Mensenhandel en Mensensmokkel, De vermissing van Vietnamese amv's en de relatie van Vietnamezen met mensenhandel en mensensmokkel in Nederland (2015 tot en met 2018), 2019. 
geren voor hun plotselinge vertrek of op een eventuele connectie met mensenhandel. Het is denkbaar dat dit verschilt voor jongeren uit relatief veilige landen (bijvoorbeeld Marokko) en voor jongeren die weliswaar uit gevaarlijke situaties kunnen komen, maar die door de strenge regelgeving verwachten weinig kans te maken op een verblijfsvergunning in Nederland.

De Vietnamese jongeren uit het APM onderzoek vertonen een deels afwijkend patroon. Van hen is een groter gedeelte tussen de 15 en 17 jaar oud, het aandeel meisjes is groter (35\% tegen $10 \%$ ) en ze komen vaker uit de Beschermde Opvang, waar ze ook relatief vaak worden geplaatst, omdat de groep kwetsbaar lijkt te zijn voor mensenhandel. Zij zijn zelden al eerder in een andere EU-lidstaat aangetroffen en voor hen worden relatief minder Dublin-claims ontvangen.

Het EMM-onderzoek richtte zich op deze Vietnamese groep en de relatie van Vietnamezen met mensenhandel en mensensmokkel. Het onderzoek betrof 78 Vietnamese alleenstaande minderjarigen die in de periode 2015 tot en met 2018 zijn verdwenen. De onderzoekers concludeerden dat Nederland voor Vietnamezen die naar Europa migreren een transitland lijkt te zijn, op weg naar het Verenigd Koninkrijk. De asielprocedure en de speciale positie die minderjarigen in Nederland hebben, worden daarvoor benut. Relatief veel Vietnamezen, van wie overigens wordt vermoed dat zij niet allemaal minderjarig zijn, worden uiteindelijk in het Verenigd Koninkrijk aangetroffen, waar zij volgens de onderzoekers slachtoffer van uitbuiting kunnen worden, bijvoorbeeld in de hennepteelt. ${ }^{23}$ In Nederland zijn daar in het EMM-onderzoek geen bewijzen voor gevonden. De verdwijningen zijn hardnekkig. Nadat Vietnamese jongeren zijn gevonden, vertrekken ze vaak opnieuw, ook na opname in de gesloten jeugdzorg. Het vertrek lijkt vaak georganiseerd. De jongeren vertrekken in groepjes, zijn voor een aanstaand vertrek onrustig, slapen dan met hun kleren aan, controleren of ramen en deuren open kunnen en soms worden verdachte auto's rondom de opvang gesignaleerd. ${ }^{24}$

Tussen 2010 en 2020 zijn in totaal ruim 2.500 jongeren uit de asielopvang verdwenen, van wie ruim 100 uit de Beschermde Opvang. ${ }^{25}$ In de Nidos Jaarverslagen van 2019 en 2020 staat dat het aantal met onbekende bestemming vertrokken jongeren is toegenomen. Het gaat vooral om jongeren uit 'veilige herkomstlanden', zoals Marokko en Tunesië. Dat zijn landen waar 'over het algemeen geen sprake is van vervolging bijvoorbeeld vanwege ras of geloof; foltering; onmenselijke behande-

23 Zie ook I. Schoenmakers, B. Bremers \& A. van Wijk, Oosterse teelt. Vietnamezen in de hennepteelt, Arnhem 2012: Bureau Beke.

24 Expertisecentrum Mensenhandel en Mensensmokkel, De vermissing van Vietnamese amv's en de relatie van Vietnamezen met mensenhandel en mensensmokkel in Nederland (2015 tot en met 2018), 2019.

25 www.nrc.nl/nieuws/2020/01/13/2500-kwetsbare-jonge-asielzoekersverdwenen-a3986602. ling, ${ }^{26}$ waardoor zij zelden in aanmerking komen voor een asielvergunning. Zij doen ook niet allemaal een asielaanvraag of vertrekken vaak al binnen drie maanden na aankomst, voordat zij de uitslag op hun aanvraag hebben ontvangen.

\section{Conclusie: zorgen en verplichtingen}

Aanpassingen in de opvang, zoals de start van de Beschermde Opvang voor slachtoffers van mensenhandel en voor alleenstaande minderjarigen die daar slachtoffer van dreigen te worden, hebben de verdwijningen van alleenstaande minderjarige vluchtelingen niet weten te stoppen. Cijfermatig is relatief veel bekend over in $\mathrm{Ne}$ derland verdwenen alleenstaande minderjarigen, maar over hoe het hen vergaat, is te weinig bekend om een sluitend antwoord te geven op de vraag of zij slachtoffer worden van mensenhandel of dat er andere zaken aan de hand zijn en het maakt het ook moeilijk om effectief beleid te maken tegen verdwijningen. Van sommige vertrokken jongeren weten we - uit verhalen van de jongeren zelf, hun opvangouders of mentoren - dat zij de benen namen toen hun 18e verjaardag naderde, de opvang zou eindigen en uitzetting dreigde. Enkelen reisden vermoedelijk door naar familie elders in Europa, anderen bleven illegaal in Nederland. Op dat moment waren er geen aanwijzingen voor mensenhandel, maar hoe deze jongeren zich uiteindelijk redden, is de vraag en we weten dat uitbuiting van (voormalige) alleenstaande minderjarigen in de illegaliteit voorkomt.

Over het lot van de verdwenen jongeren die niet meer worden aangetroffen door autoriteiten of door onderzoekers, is nog minder bekend. Er blijven dan ook verontrustende signalen komen van wetenschappers, belangenorganisaties en journalisten, waarbij soms de link naar mogelijke mensenhandel wordt gelegd.

Jongeren die verdwijnen, verdienen zorg en aandacht van de Nederlandse overheid. Voor jongeren die verdwijnen uit de Beschermde Opvang geldt dit extra vanwege hun verhoogde kwetsbaarheid. In het rapport van het EASO (Europees Ondersteuningsbureau voor asielzaken) over het belang van het kind in asielprocedures wordt erop gewezen dat de overheid bij alle minderjarigen zo snel mogelijk risicofactoren op moet sporen, zoals het hebben ervaren van (potentieel) traumatiserende gebeurtenissen, misbruik, mishandeling, uitbuiting of indicaties daarvoor. Een professionele, multidisciplinaire vaststelling van het belang van het kind, voorafgaand aan een migratierechtelijke procedure, waarbij voldoende tijd wordt uitgetrokken voor het opbouwen van vertrouwen, is daarbij van wezenlijk belang zodat een alleenstaande minderjarige die slachtoffer van

26 www.rijksoverheid.nl/onderwerpen/asielbeleid/vraag-en-antwoord/ lijst-van-veilige-landen-van-herkomst. 
mensenhandel is of dreigt te worden en mogelijk op het punt staat te verdwijnen, zijn of haar verhaal durft te doen. ${ }^{27}$ Voogden geven aan dat alleenstaande minderjarigen, vooral kort na aankomst, weinig communicatief zijn en (nog) iedereen in hun omgeving wantrouwen. ${ }^{28}$ Mentor en voogd zouden jongeren in alle rust moeten kunnen helpen hun levensverhaal te delen voordat in contact met migratie-autoriteiten een traject in het migratierecht wordt ingezet. ${ }^{29}$

Een kindgericht beschermingssysteem kan ook helpen om te voorkomen dat een alleenstaand minderjarig slachtoffer van mensenhandel kiest voor de relatief grotere zekerheid van de asielprocedure, waardoor het verhaal van het slachtoffer niet boven water komt en daders buiten schot blijven. De actieve opsporing van daders, waarbij internationaal wordt samengewerkt en informatie wordt gedeeld, is een verplichting die voorkomt uit het VN-Protocol ter voorkoming van mensenhandel.

Het naderen van de $18 \mathrm{e}$ verjaardag van jongeren zonder verblijfsrecht komt in diverse onderzoeken naar voren als een moment dat verdwijningen dreigen. Het is van belang jongeren tijdig zo goed mogelijk voor te bereiden op hun toekomst buiten Nederland, terugkeerbegeleiding te organiseren en te monitoren. Het zou helpen als de leeftijdsgrens van 18 jaar in het vreemdelingenrecht flexibeler gehanteerd kan worden, zoals nu al het geval is binnen het jeugd(straf)recht. Jongvolwassenen kunnen tot hun 23e jaar worden veroordeeld volgens het jeugdstrafrecht, verlengde jeugdhulp is ook mogelijk tot 23 jaar en kinderen in pleeggezinnen kunnen daar tot hun 21e blijven. Een flexibeler leeftijdsgrens in het vreemdelingenrecht zou betekenen dat jongeren zonder verblijfstitel wat meer tijd hebben om zich voor te bereiden op een zelfstandig bestaan als volwassene, waar zich dat bestaan ook afspeelt. ${ }^{30}$

Tot slot zou meer onderzoek gedaan moeten worden naar het lot van verdwenen alleenstaande minderjarigen en zou bij alle verdwijningen goed naar de kinderen gezocht moeten worden. Nederland heeft meermalen laten zien hoe breed gedragen de zoektocht naar kinderen kan zijn als die om onbekende, en dús verontrusten- de, redenen uit het zicht van hun ouders zijn geraakt. ${ }^{31}$ Een dergelijke inzet mag ook verwacht worden voor verdwenen gevluchte jongeren.
Oan Os, A.E. Zijlstra, WJ. Post, EJ. Knorth \& ME. Kalverboer, 'Finding keys: A systematic review of barriers and facilitators for refugee children's disclosure of their life stories', Trauma, Violence, \& Abuse 2020 21(2), p. 242-260.

28 C. van Os, E. Zijlstra, E.J. Knorth, W. Post \& M. Kalverboer, 'Methodology for the assessment of the best interests of the child for recently arrived unaccompanied refugee minors', in: M. Sedmak, B. Sauer \& B. Gornik. (Eds). Unaccompanied children in European migration ans asylum practices: in whose best interests? (p. 59-85). Abbingdon UK 2018: Routledge.

29 J. Bhabha, Child Migration \& Human Rights in a Global Age. Princeton, New Jersey 2014: Princeton University Press.

30 C. Bailleul, 'Coping strategies of unaccompanied minors lacking protection within the French context', in: M. Sedmak, B. Sauer \& B. Gornik (Eds), Unaccompanied children in European migration and asylum practices: in whose best interests? (p. 134-154), Abbingdon UK 2018: Routledge; I. Kulu-Glasgow, M. van der Meer, M. Smit \& S. Noyon, Een onzekere toekomst (cahier 2021-17), Den Haag 2021: WODC.
31 Zie bijvoorbeeld www.nu.nl/binnenland/3478609/chronologievermiste-broers-ruben-en-julian.html. 